\title{
Student Experiments on the Topic of Micro-plastics in the Environment for Secondary Education Level II: The Coffee Pad Machine Experiment and Sediment Analysis
}

\author{
Sarah Vortmann ${ }^{1}$, Dominique Remy ${ }^{2}$, Jörg Klasmeier ${ }^{3}$, Marco Beeken ${ }^{1, *}$ \\ ${ }^{1}$ University of Osnabrück, Department of Chemistry Education, Osnabrück, Germany \\ ${ }^{2}$ University of Osnabrück, Department of Biology Osnabrück, Germany \\ ${ }^{3}$ University of Osnabrück, Department of Environmental Systems Research Osnabrück, Germany \\ *Corresponding author: Marco.Beeken@uni-osnabrueck.de
}

Received January 04, 2019; Revised February 18, 2019; Accepted March 24, 2019

\begin{abstract}
Two simple laboratory experiments for addressing the issue of microplastics in the aqueous environment in science teaching are developed. Extraction of microbeads from cosmetic products using a coffee pad machine makes students aware of the potential emission of microplastics into the environment by using these products. Density separation of microplastic particles from beach sediment samples on the other hand demonstrates the difficulty of dealing with the problem once the particles have entered the environment. Using the low-cost experimental set-up facilitates integration of the microplastics' topic into laboratory teaching making science lessons vivid and more interesting.
\end{abstract}

Keywords: microplastic, model experiment, environmental chemistry, chemistry in context, low-cost method, coffee pad machine, science communication, sediment analysis, density separation procedure, cosmetics

Cite This Article: Sarah Vortmann, Dominique Remy, Jörg Klasmeier, and Marco Beeken, "Student Experiments on the Topic of Micro-plastics in the Environment for Secondary Education Level II: The Coffee Pad Machine Experiment and Sediment Analysis.” World Journal of Chemical Education, vol. 7, no. 2 (2019): 96-101. doi: 10.12691/wjce-7-2-9.

\section{Introduction}

The topic of „micro-plastics and their impact on the environment" has not only gained increasing media attention in recent years but has also become a major new field of research around the world. Currently, this topic is increasingly discussed in society, politics and science. Although there is increasing interest to integrate this problem in the school context, it has not yet found an adequate expression in teaching schedules. Especially in science teaching inclusion of such topical issues in laboratory courses is an important factor in raising interest of pupils for learning matter. As a first means to address the microplastic issue in laboratory teaching, two innovative model experiments for use on the upper secondary level have been developed. The focus is on teaching chemistry in context. The goal is to make a particular contribution to environmental education by helping students to carry out adapted scientific experiments and thus further improve their analytical skills. Current scientific research serves as the basis and can be made available to the educational process with the help of such targeted experiments. On the one hand, primary microplastics will be extracted from cosmetic articles using a coffee pad machine. On the other hand, the question will be tackled, of how microplastics already introduced into the environment, both primary and secondary, can be removed from sediment using a density separation method. This helps the students making the connection between the direct anthropogenic input of microplastics into the environment through cosmetic products and the difficulties of removing microplastics once emitted. The experiments show a high relevance to everyday life and can be easily integrated and replicated in the lesson through the implementation of the low-cost methods described below.

\section{The Sediment Analysis}

Contamination of water bodies by microplastics is an increasing problem. Whether secondary or primary microplastics, at some point a large portion of the plastic particles will sink to the water table and mix with the sediment of the sub-soil [1]. Also, microplastics already contaminate beach sediments all over the world [2]. At this stage, students will perform a model experiment that shows, in a simplified manner, the environmental impact 
of sediment being contaminated with microplastics. The basis for this is density separation: Due to the different densities of sediment (quartz sand: approx. $2.6 \mathrm{~g} / \mathrm{cm}^{3}$ ) and plastic (0.8 g (polypropylene) - 1.4 g (polyvinylchloride)), these two materials can be separated with the help of a suitable solution [3]. The content of this experiment is the extraction of microplastics from a solid sample with the help of a self-constructed density separation apparatus. The aim is to separate the plastic particles from the sediment, determine their number and subsequently analyse them. The apparatus is low cost and made from simple everyday objects [4]. The students should be able to reflect on whether this method can be used as a model experiment in practice in science.

\subsection{Devices and Chemicals}

Everyday objects from plastics, snap-top glasses, coffee mill, tripod, clamps, 2 false PETs, muffle valve (valve), aquarium pump with air nozzle and hose, 1 hose valve, Teflon tape, 1 carpet knife, 1 glass rod, 1 funnel, 1 pleated filter, 1 x $200 \mathrm{ml}$ beaker, 1 x 1 litre beaker, 1 hotplate, 1 secateurs, $\mathrm{NaCl}$, sucrose and water.

\subsection{Preparing the Micro-plastics}

In the production of microplastics for later use in a model experiment, known plastic everyday objects are coarsely reduced in size with secateurs and ground with an electric coffee grinder to a grain size of $0.5-2 \mathrm{~mm}$. Then, the microplastic particles are transferred into small snaptop vials and labelled (Figure 1).

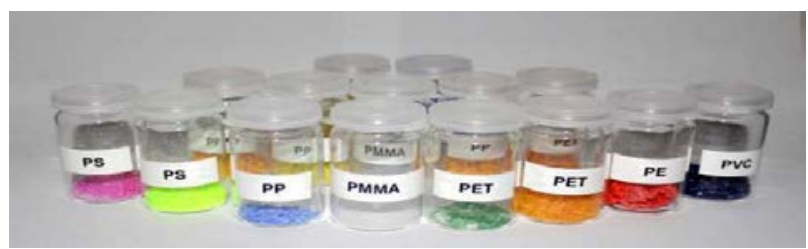

Figure 1. Snap top vials with micro-plastic samples for the model experiment of the sediment analysis. These were made as various everyday objects, which can still be assigned with the help of the colours even after the analysis

The labelling was created using the existing recycling codes on the everyday objects that roughly indicate the type of plastic used [5]. The objects were deliberately selected according to these recycling codes to create a vivid everyday reference for the students (Table 1).

Table 1. Recycling codes [4]

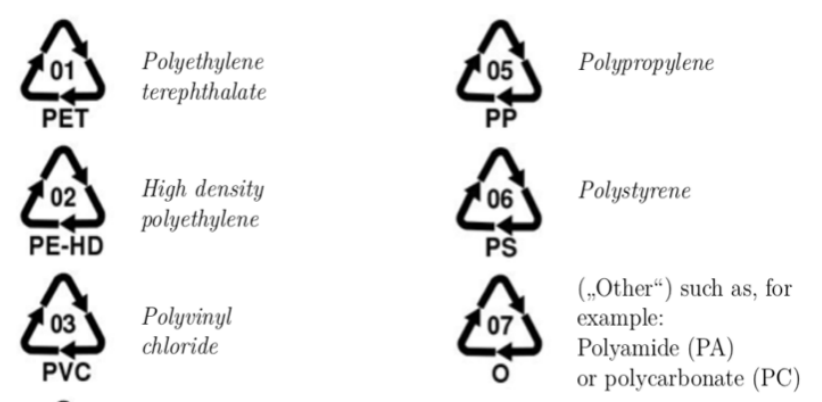

PE-LD polyethylene
The everyday reference would be further boosted by having students independently bring in typical objects made of a particular type of plastic on their own. In order to identify the types of plastic more accurately, FTIR analysis is recommended [6]. Then, cleaned sand samples (washed aquarium sand) were spiked with 10-20 different microplastic particles. The number, colour and type of plastics are determined. For this purpose, $40 \mathrm{~g}$ of sand including the microplastic particles are transferred to the snap-top vials and numbered (Figure 2).

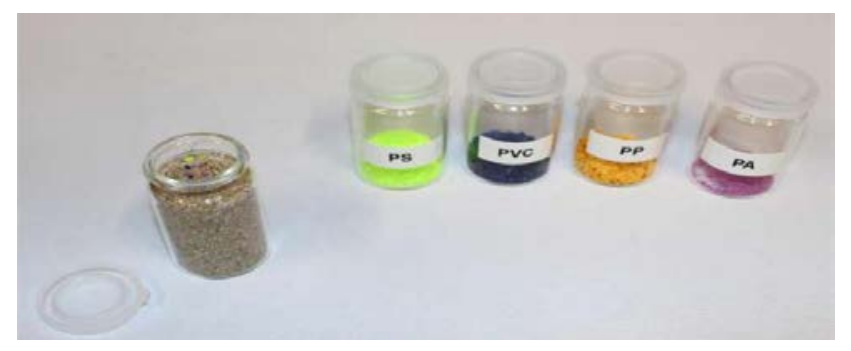

Figure 2. Snap-top vials with sediment and microplastic samples (left) for the model experiment of sediment analysis. The reserve containers with microplastic contents are located on the right. $40 \mathrm{~g}$ of sediment are contaminated here with a known number of microplastic particles. The type of plastic and the number remains initially unknown to the students. Subsequently, this sample is analysed by means of the sediment separation procedure, sand is separated from plastic and then re-assigned to the samples or everyday objects

The type of plastic should be clearly distinguishable from one another in terms of colour in order to facilitate the subsequent assignment and to guarantee a clear outcome of the experiments [7]. The samples can then be independently analysed by the students and thereby contribute to teaching which is orientated towards activity and problem solving [8].

\subsection{Preparation of the NaCl-Sucrose Solution}

A solution with the highest possible density is needed in order to perform this experiment. A zinc chloride $\left(\mathrm{ZnCI}_{2}\right)$ solution is frequently used for this purpose in scientific studies [9]. As this experiment would be unsuitable for students due to the environmentally harmful nature of these chemicals, sodium chloride $(\mathrm{NaCl})$ and sucrose are used instead. First, a saturated $\mathrm{NaCl}$ solution is produced. Sucrose is then added with constant stirring until a density of approximately $1.38 \mathrm{~g} / \mathrm{l}$ is reached. In order to accelerate this process, it is recommended to heat the solution slightly with a hotplate. The chemicals are readily obtained from the supermarket. For 1 litre of solution, approximately $360 \mathrm{~g} \mathrm{NaCl}$ and 1,300 - 1,600 g sucrose are needed. The preparation of the solution takes about 20 minutes and should be finished and provided by the teacher before the experiment.

\subsection{Set-up of the Apparatus}

The set-up of the apparatus can be carried out either before the student experiments by the teacher or independently with the students as part of the experiment. For the set-up, at least 10 minutes should be scheduled (Table 1). This requires a tripod with appropriate clamps, two PET bottles, one aquarium pump with hose and air nozzle, a carpet knife, Teflon tape, pleated filter, funnel, 
funnel stand and a socket slide valve (diameter 1 inch) serving as stopcock. The apparatus is constructed according to Figure 3.

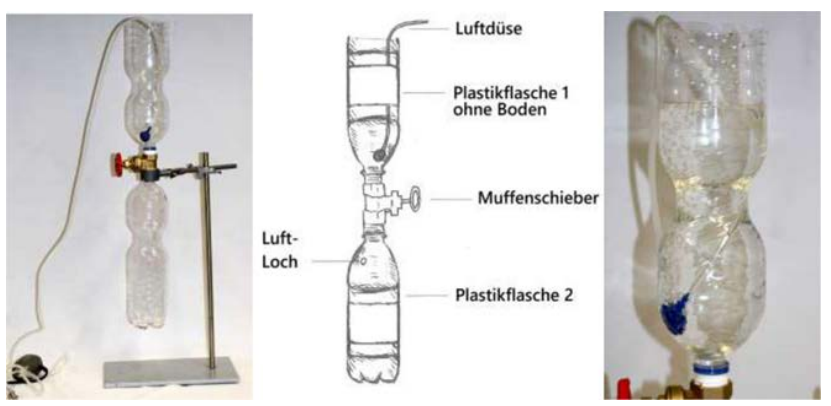

Figure 3. The apparatus for sediment analysis with the aid of density separation. On the left, the entire apparatus is shown before being filled with $\mathrm{NaCl}$ sucrose solution; on the right, the apparatus is shown after being filled and subsequent air supply. A separation of the sediment sample by circulation is assured by the rising bubbles. The upper bottle (right) is filled with the separating liquid and the muffle valve is closed in advance. Then, the air supply is employed, so that fine bubbles rise up

The threads of the bottles are wrapped with Teflon tape before connected with the muffle valve to ensure that the apparatus is best tightly sealed. Overall, the PET bottles can be re-used three times. Once both bottles are connected with the muffle valve, they are fixed in the middle with the help of the tripod. The next step is to remove the bottom with the help of a carpet knife. In the lower bottle a small hole is cut in the upper edge area, either with the help of a heated glass rod or with a carpet knife. This will allow excess air to escape later from the lower bottle. After filling the upper bottle with NaClsucrose solution, the air nozzle of the aquarium pump is hooked to a connecting hose in the upper bottle and fixed with tape to the edge. To regulate the flow of the air supply, a small valve was inserted into the air hose, which can be found in the right size in aquarium shops. Before filling the device, it must be checked that the muffle valve is closed, so that only the upper bottle is filled with solution. The density separation takes place in the upper area of the apparatus by slowly spreading sand into the water circulating through the column of air.

\subsection{Implementation}

The students start by setting up the apparatus properly and checking for leaks. The muffle valve must be kept closed and the aquarium pump checked for functionality. In the next step, the upper plastic bottle is filled with $\mathrm{NaCl}$-sucrose solution to $3 / 4$ and the air supply is hooked up and turned on. For analysis of the spiked samples, $40 \mathrm{~g}$ of sand is slowly and gradually sprinkled into the upper bottle. It is important to ensure that not too much sediment enters the apparatus at a time to avoid clumping. One minute after the complete sample has been filled in, the air supply is switched off. After another 2-3 minutes the sediment has completely settled on the ground with the microplastic particles in the upper area of the suspension. Depending on their density they partly reside on the surface of the solution and partly in the water column. Then, the muffle valve is gently opened to drain the sediment at the bottom into the collecting bottle. Approximately $75 \%$ of the total volume is removed from the top bottle. The 140 microplastic particles were now visibly separated from the sediment with the help of the apparatus. The plastic particles are completely in the upper bottle, whilst most of the sediment is in the lower bottle (Figure 4).

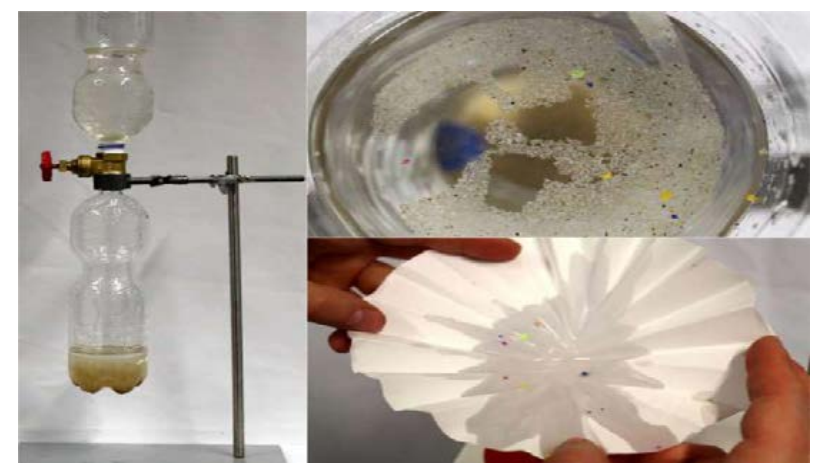

Figure 4. The result of the sediment analysis. On the left, the apparatus is shown after the separation. The air supply has already been removed. A suspension of micro-plastic particles and $\mathrm{NaCl}$-sucrose solution are located in the upper area. The excess sediment has been collected in the lower area of the apparatus. Sediment and micro-plastics are now separated. At the top right, you can recognise some coloured microplastic particles on the suspension surface. After filtering the solution with a pleated filter, the microplastic fragments can be analysed for their origin (bottom right)

Care must be taken to ensure that no microplastic particles suspended in the separating fluid are accidentally drained into the lower bottle. The suspension is finally filtered using a pleated filter. For this purpose, the socket slide valve is closed and unscrewed from the bottle. The suspension can now easily be filtered over a pleated filter. It is important to rinse the bottle several times with water to make sure that no microplastic particles remain in the apparatus. The hose for the air supply should also be checked for microplastic residues and rinsed appropriately. After that, the microplastic particles can be sorted by colour to determine their origin and their properties. Plan about 30 minutes for the implementation, including filtration (Table 2).

\subsection{Recommendations for Implementation}

The equipment must first be checked for leaks. With the help of teflon tape, the screw cap of the bottle can be sealed. Keep in mind that the density of the $\mathrm{NaCl}$ - sucrose solution used should be at least as high as the highest density of plastics used. To guarantee a clearly interpretable outcome of the student experiment, it is advantageous to use only plastic objects of moderate density PVC (density approx. $1.3 \mathrm{~g} / \mathrm{mL}$ ) is therefore of limited suitability, but can serve as reference sample for possible false negative outcomes.

Table 2. Time Recommendations for implementation

\begin{tabular}{lll}
\hline Number & Segment & Time \\
\hline 1 & $\begin{array}{l}\text { Preparation of the } \\
\text { Micro-plastics preparation }\end{array}$ & 10 minutes/plastic grade \\
2 & $\begin{array}{l}\text { Preparation of NaCl Sucrose } \\
\text { solution }\end{array}$ & 20 minutes \\
3 & Set-up of the apparatus & 10 minutes \\
4 & Implementation & 10 minutes \\
5 & Filtration of the suspension & 15 minutes \\
\hline
\end{tabular}




\section{Analysis of Cosmetic}

Isolating microplastics from cosmetic products by using a coffee machine is a vivid method to show students a primary source of microplastics through the consumption of contaminated products [3]. How much microplastic is there in a cosmetic peeling?

With simple means, it is possible to isolate the so-called microbeads from cosmetic products. A coffee pod machine with a fine sieve insert provides a good filter system to separate microparticles from the liquid or solid matrices. The matrix is removed by the warm/hot water flow, while the microplastic particles remain in the sieve insert. The aim of this experiment is to quite plainly show the emission pathway of primary microplastics into wastewater after use of cosmetic products. Here, we focus on the source of primary microplastics, while in the first experiment a method for determining the resulting environmental contamination is depicted.

\subsection{Devices and Chemicals}

Cosmetic peeling, coffee pad machine, permanent coffee filter, precision balance, graph paper, binoculars or magnifying glass.

For this experiment, a cosmetic peeling containing visible plastic beads is best suited. The main ingredients of cosmetic products must be included in the ingredients list on the packaging. With the help of the Purchasing Guide of the German Federal Government for the Environment and Nature Conservation Germany (BUND), which is a registered association, suitable cosmetic products can be easily found [10]. A visit to the supermarket and an analysis of the local products using the codecheck.info app are also very helpful [11]. For the experiment described here, a commercially available peeling product was selected. A standard water-filled coffee pad machine, a permanent coffee filter and a precision balance are needed for the analysis (Figure 5). For subsequent drying, it is advisable to provide kitchen paper and a hair dryer. Extracted microplastic particles are counted under a binocular with the help of commercial graph paper on which an area of $16 \mathrm{~cm}^{2}$ has been marked.

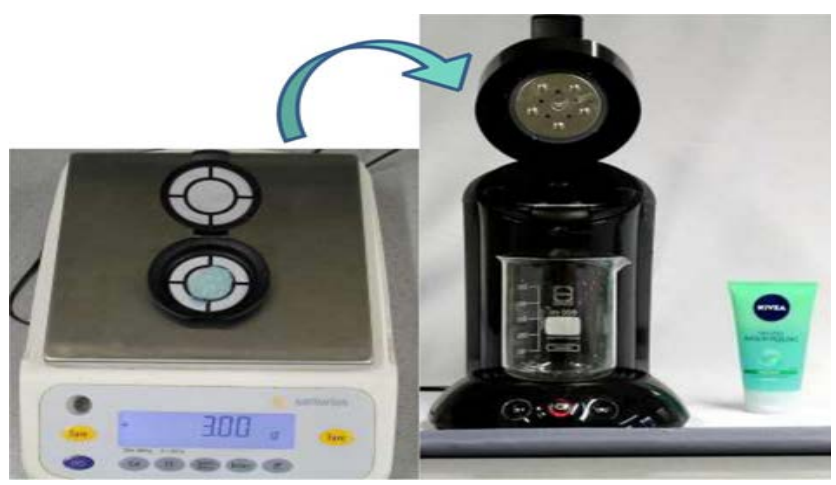

Figure 5. Weigh out 3 grams of cosmetic peeling in a permanent coffee filter (left) and transfer to the coffee pad machine (right). Then the sample is rinsed up to seven times until no more gel-like components of the peeling are present

\subsection{Implementation}

The students first weigh 1-3 g of the cosmetic peeling directly into the permanent coffee filter. The filter is then firmly closed and transferred into the coffee pad machine (Figure 5). Extraction is performed by rinsing the material up to six times until the microbeads are visibly separated in the sieve with no other residues of the original gel. Subsequently, the filter is carefully dried by utilizing the suction effect of blotting paper and a conventional hair drier. Once the permanent filter has been dried, the students can weigh the sample and analyze it with the help of a specially designed optical method (Figure 6). To determine the mass of the particles, the filter is weighed with and without micro-plastic particles and the difference determined. To determine the particle number, the particles are homogeneously distributed and counted on a graph paper. Due to the high particle count it is sufficient to count one square $\left(1 \mathrm{~cm}^{2}\right)$ of the total area and to extrapolate the result to the total area of $16 \mathrm{~cm}^{2}$ (see example calculation). Overall, the implementation including the following calculations takes 50 minutes (Table 3).

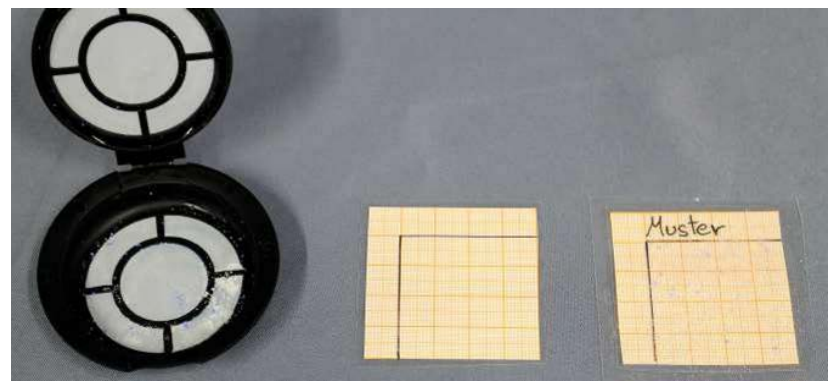

Figure 6. Result after drying of the permanent filter. The sample can now be weighed and counted with the help of the graph paper. A sample example is provided on the right

Table 3. Time Recommendations for implementation

\begin{tabular}{lll}
\hline Number & Segment & Time \\
\hline 1 & Set-up & 5 minutes \\
2 & Implementation & 20 minutes \\
3 & Evaluation and calculation & 30 minutes \\
\hline
\end{tabular}

In order to relate the amount obtained to the total emission of microbeads via this pathway [12], an extrapolation to the total product volume (in this case $150 \mathrm{ml}$ ) is made. Total annual emission can be calculated by multiplying the average concentration with the estimated annual product consumption of a single person assuming a certain percentage of consumers in Germany (e.g. 1/3 of the population).

\subsubsection{Example Calculation}

Starting from three microplastic particles identified on one square (area: $1 \mathrm{~cm}^{2}$ ) of the graph paper (total area: 16 $\mathrm{cm}^{2}$ ) the total number of particles in the homogeneously distributed sample is estimated to $3 \times 16=48$ particles.

These 48 microplastic particles were extracted from $3 \mathrm{~g}$ sample material. Assuming a density of $1 \mathrm{~g}$ per $\mathrm{mL}$, the number of particles in the peeling package (volume: $150 \mathrm{ml}$ ) is 50 times higher resulting in 2,400 particles. 


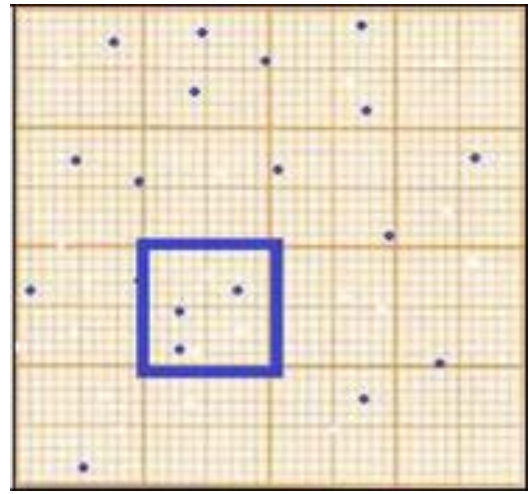

Figure 7. Particle counting with graph paper. Particles on $1 \mathrm{~cm}^{2}$ surface are counted and extrapolated to the total area covered with the sample

\subsubsection{Calculation of Microplastics Mass}

The mass in the entire peeling $(150 \mathrm{~mL})$ is again 50 times of output weight. From the average result of our experiments, we estimate that $0.004 \mathrm{~g}$ of microplastics can be extracted using the coffee pad machine from $3 \mathrm{~g}$ of the sample. From this, it is calculated that a total mass of $0.2 \mathrm{~g}$ of microplastics are hidden in a peeling package of $150 \mathrm{ml}$.

\subsubsection{Calculation of Particle Count and Mass of a Person per Year}

In the next step, we assume that one package of peeling lasts exactly one week for one person. To calculate the annual consumption of this person, the number of particles in the package $(2,400)$ is multiplied by 52 weeks. This calculation results in a particle count of 24,600 particles emitted per year by one consumer. Accordingly, the respective mass of microplastics calculates to $0.2 \mathrm{~g}$ x $52=10.4 \mathrm{~g}$ per year and consumer.

\subsubsection{Calculation of Total Emission of Microplastics from the Product (Particle Count and Mass)}

However, not every person uses the product. For estimation of the total annual emission we now assume that a fraction of $1 / 5$ of the total population uses it. For Germany with a total population of 81 million people, this accounts to 16.2 million consumers of the peeling product that here serves as a model compound. Multiplying the annual emission of one consumer calculated above by this number leads to the estimated total microplastics emission for Germany by the use of the model product. For the particle number, we obtain

$$
\begin{aligned}
& 16,200,000 \times 24,600 \\
& =398,520,000,000 \text { particles per year }
\end{aligned}
$$

Accordingly, the total emitted mass is estimated to

$$
16,200,000 \times 0.2=3,240,000 \text { g per year. }
$$

Thus, approximately 398.5 billion particles or 3.24 tons of microplastics would be released into wastewater and thus into the environment during one year based on a oneoff consumption of a peeling package used by of one fifth of the population of Germany,

Through this stage, the students obtain a direct picture of the high amount of microplastics potentially introduced into the environment, thereby enhancing their skills for evaluation of environmentally harmful products.

\subsection{Tips for the Implementation}

It is important to ensure that no gel residues remain in the permanent filter. These would falsify the mass determination by weighing. A drying cabinet can also be used as an alternative to the hair dryer. However, this extends the implementation time by at least 10 minutes. In order to guide the consumer, the BUND has issued a purchasing guide, which can also be used at this stage in the school experiment: students may independently search for and select cosmetic products which they suspect to contain microplastic particles. Alternatively, the website codecheck.info can be used to identify products most likely containing microplastics [11].

\section{Educational Legitimation and Conclusion}

Since microplastics are a global and ever-growing problem, awareness must be raised of the negative effects of these materials on the environment and the subsequent prevention of waste in the future in the first place, so that the introduction of plastics into the seas and inland waters can be stopped. In order to create a social change, it is important, as already mentioned, to raise the population's awareness of the problem as early as possible. For this reason, the integration of this topic into school curricula is more than sensible. In the course of the experiments it became clear that the skills of the students to realize and critically assess the environmental contamination through microplastics were trained. The students considered the contamination of beach sediment by microplastic increasingly critical. Especially those students, who had previously addressed the issue of microplastics and their impact on the environment, were quickly aware of negative consequences of microplastics in the environment with the help of the experiments. In addition, the results of the cosmetics experiment were registered with astonishment. Previously, most students had not been aware of the potential impact of cosmetics as a cause of environmental pollution by plastic. The extent of the problem was exemplified with the help of hypothetical but not unrealistic calculations.

Based on the experiments designed here, a first step in the right direction has been initiated. Addressing the consequences of plastics' introduction into the environment by demonstrative experiments makes students to directly experience what otherwise remains hidden. In addition to the detailed knowledge of the emission and transport pathways, however, more didactic concepts must be developed to tackle this serious environmental problem.

To convey chemistry in context is the focus of the conception of these experiments [12]. For this reason, it will be important in the future to devise further experiments on a scientific and school level in order to make the topic of micro-plastics and their impact more visible to the public. A major goal in this respect should be to integrate this topic into everyday school lessons. The low-cost-methods established in this concept significantly simplify the set-up and realization of the experiments by teachers not at least due to easy procurement [4] reover, 
the outcome of natural science experiments with the use of everyday objects is probably more accessible to students than demonstration by complex setups. In this respect, we also think that science lessons with a clear reference to actual everyday problems can create more sustainable knowledge than many a theoretical school lesson.

\section{References}

[1] Van Cauwenberghe, L., Vanreusel, A., Mees, J., and Janssen, C. R., "Micro-plastic pollution in deep-sea sediments", Environmental Pollution, 182, 495-499, 2013.

[2] Nuelle, M.-T., Dekiff, J. H., Remy, D., Fries E. "A new analytical approach for monitoring microplastics in marine sediments", Environmental Pollution 184, 161-169, 2014.

[3] Jekel, M., Miklos, D., Obermaier, N.: Microplastics: Development of an Environmental Assessment Concept, First Considerations on the Relevance of Synthetic Polymers in the Environment, ed. Federal Environmental Agency, April 2016.

[4] Poppe, N., Markic, S., and Eilks, I., Low Cost Experimental Techniques for Science Teaching, European Commission TEMPUS, Cornelsen Scriptor, 2010, pages 9-16.

[5] Hunt, EJ, Zhang, C., Anzalone, N., and Pearce, JM "Polymer recycling codes for distributed manufacturing with 3-D printers". Resources, Conservation and Recycling, 97, 24-30, 2015.

[6] Cincinelli, A., Scopetani, C., Chelazzi, D., Lombardini, E., Martellini, T., Katsoyiannis, A., Fossi, M., C. and, Corsolini, S. "Micro-plastics in the surface waters of the Ross Sea (Antarctica): Occurrence, distribution and characterisation by FTIR",
Chemosphere, 175, 391-400, 2017.

[7] Barke, HD, Harsch, G., Marohn, A., and, Krees, S. Chemistry Education- compact version; Springer Berlin Heidelberg, 2015, 143-184.

[8] Rossa E, "Chemistry Education: Practical handbook for secondary levels I and II”, Cornelsen Scriptor, 89, 2005, [Muffle valve 1 inch amazon]

Available: https://www.amazon.de/EgoEra\%C2\%AE-

Sperrschieber-Muffenschieber-Messing-

Drehgriff/dp/B01MU9LOIR/ref=sr_1_17_sspa?ie=UTF8\& qid $=1511304588 \&$ sr $=8-17$ spons\&keywords=muffinschieber \&psc $=1$ [Accessed Nov. 2017].

[9] Claessens, M., De Meester, S., Van Landuyt, L., De Clerck, K. \& Janssen, "CR: Occurrence and distribution of micro-plastics in marine sediments along the Belgian Coast", Marine Pollution Bulletin, 300 62, 2199-2204, 2011.

[10] Ziebarth, N. "BUND Shopping Guide: Micro-plastics - the invisible danger",

Available:

https://www.bund.net/fileadmin/user_upload_bund/publikationen/ meere/meere_mikroplastik_einkaufsfuehrer.pdf [Accessed Nov. 2017].

[11] Codecheck AG,

Avialable: https://www.codecheck.info/ [Accessed Nov. 2017].

[12] Napper, IE, Bakir, A., Rowland, SJ, Thompson, "RC: Characterisation, quantity and sorptive properties of micro-plastics extracted from cosmetics”, Marine Pollution Bullrtin, 99 (1-2), 178-185, 2015.

[13] Parchmann, I., Gräsel, C., Baer, A., Nentwig, P, Demuth, R., and, Ralle, B., "Chemistry in Context" A symbiotic implementation of a context-based teaching and learning approach", International Journal of Science Education, 28 (9), 1041-1062, 2006.

(C) The Author(s) 2019. This article is an open access article distributed under the terms and conditions of the Creative Commons Attribution (CC BY) license (http://creativecommons.org/licenses/by/4.0/). 